\title{
Specific manifestations of knee osteoarthritis predict depression and anxiety years in the future: Vancouver Longitudinal Study of Early Knee Osteoarthritis
}

Eric C. Sayre ${ }^{1 *}$ (D), John M. Esdaile $e^{1,2,3}$, Jacek A. Kopec ${ }^{1,4}$, Joel Singer ${ }^{4}$, Hubert Wong ${ }^{4}$, Anona Thorne ${ }^{4}$, Ali Guermazi ${ }^{5}$, Savvas Nicolaou ${ }^{6}$ and Jolanda Cibere ${ }^{1,2}$

\begin{abstract}
Background: To evaluate whether knee osteoarthritis $(\mathrm{OA})$ manifestations predict depression and anxiety using cross-sectional and longitudinal prediction models.

Methods: A population-based cohort $(n=122)$ with knee pain, aged 40-79, was evaluated at baseline, 3 and 7 years. Baseline predictors were: age decade; sex; BMI $\geq 25$; physical exam knee effusion; crepitus; malalignment; quadriceps atrophy; flexion; flexion contracture; Kellgren-Lawrence $(\mathrm{KL}) \mathrm{x}$-ray grade $(0 / 1 / 2 / 3+)$; WOMAC pain $\geq 25$; WOMAC stiffness $\geq 25$; self-reported knee swelling; and knee OA diagnosis (no/probable/definite). Depression and anxiety, cutoffs 5+ and 7+ respectively, were measured via the Hospital Anxiety and Depression Scale. We fit logistic models at each cycle using multivariable models selected via lowest Akaike's information criterion.

Results: Baseline depression model: sex (female $O R=0.27 ; 0.10,0.76)$ and $K L$ grade $(K L 1 O R=4.21 ; 1.31,13.48)$. Three-year depression model: $K L$ grade $(K L 1 O R=18.92 ; 1.73,206.25)$. Seven-year depression model: WOMAC stiffness $\geq 25(O R=3.49 ; 1.02,11.94)$ and flexion contracture $\geq 1$ degree $(O R=0.23 ; 0.07,0.81)$. Baseline anxiety model: knee swelling $(\mathrm{OR}=4.11 ; 1.51,11.13)$ and age $(50-59$ vs. 40-49 $\mathrm{OR}=0.31[0.11,0.85] ; 60-69 \mathrm{OR}=0.07[0.01$, $0.42])$. Three-year anxiety model: WOMAC stiffness $\geq 25(\mathrm{OR}=5.80 ; 1.23,27.29)$ and $\mathrm{KL}$ grade $(\mathrm{KL} 1 \mathrm{OR}=6.25 ; 1.04$, 37.65). Seven-year anxiety model: sex (female $O R=2.71 ; 0.87,8.46$ ).
\end{abstract}

Conclusion: Specific knee OA-related manifestations predict depression and anxiety cross-sectionally, 3 years in the future, and for depression, 7 years in the future. This information may prove useful to clinicians in helping to identify patients most at risk of present or future depression and anxiety, thus facilitating preemptive discussions that may help counter that risk.

Keywords: Osteoarthritis (OA), Depression, Anxiety, Magnetic resonance imaging (MRI)

\footnotetext{
* Correspondence: esayre@arthritisresearch.ca

1 Arthritis Research Canada, 5591 No. 3 Road, Richmond, BC V6X 2C7, Canada

Full list of author information is available at the end of the article
}

(c) The Author(s). 2020 Open Access This article is licensed under a Creative Commons Attribution 4.0 International License, which permits use, sharing, adaptation, distribution and reproduction in any medium or format, as long as you give appropriate credit to the original author(s) and the source, provide a link to the Creative Commons licence, and indicate if changes were made. The images or other third party material in this article are included in the article's Creative Commons licence, unless indicated otherwise in a credit line to the material. If material is not included in the article's Creative Commons licence and your intended use is not permitted by statutory regulation or exceeds the permitted use, you will need to obtain permission directly from the copyright holder. To view a copy of this licence, visit http://creativecommons.org/licenses/by/4.0/ The Creative Commons Public Domain Dedication waiver (http://creativecommons.org/publicdomain/zero/1.0/) applies to the data made available in this article, unless otherwise stated in a credit line to the data. 


\section{Background}

Osteoarthritis (OA) is a highly prevalent, disabling and costly condition. In the province of British Columbia, Canada, $11 \%$ of the adult $(18+)$ population were reported to have OA in a study evaluating administrative data [1]. In the U.S., clinical OA (defined on the basis of symptoms and physical examination findings) was seen in 27 million adults in 2008 [2]. Symptomatic radiographic knee OA affects $9.5 \%$ of elderly adults aged 63 years and older [3]. OA is more prevalent with older age and in obese people and thus, OA constitutes an increasing public health burden. In Canada, the total economic burden for OA, including direct and indirect costs, was estimated at $\$ 27.5$ billion in 2010, and the cumulative economic burden between 2010 and 2040 is estimated to be $\$ 1.45$ trillion [4].

Depression and anxiety are common in OA [5], and it would be valuable to identify those most at risk amongst a clinician's patients, as such foreknowledge would facilitate preemptive discussions that could counter that risk. Unfortunately, within the body of research on depression/anxiety in OA populations (both knee OA and in other joints), relatively few have investigated the specific predictors of depression/anxiety in OA [6-19], and the majority have been cross-sectional. Only four studies investigated possible predictive associations between present-day OA and future depression or anxiety, with predictors including number of painful joints, gait speed, pain, disability and fatigue $[12,15,16,19]$. In the present study, we aim to develop models predicting both present-day and future depression or anxiety from a much larger set of knee OA-related factors easily accessible to clinicians. This study is done on a populationbased cohort with knee pain (mild to severe), and includes subjects with radiographic OA, as well as those with pre-radiographic OA, the latter of which tends to be undiagnosed OA in general practice. Since many individual aspects of the OA disease process may be present in a subject without the OA diagnosis itself-for example stiffness, knee swelling or low-grade osteophytes-this therefore represents an expansion of the target population potentially impacted by our findings, beyond simply those with an OA diagnosis.

\section{Methods}

\section{Study population}

The cohort was recruited between 2002 and 2005 and has been described previously in Cibere et al. [20] In brief, 255 subjects aged 40-79 with knee pain were recruited as a population-based random sample in Vancouver, Canada. Stratified sampling was used in order to achieve equal representation within age decades and gender. The pain criteria for inclusion specifically were, "pain, aching, or discomfort in or around the knee on most days of the month at any time in the past" [20], and "any pain, aching, or discomfort in or around the knee in the past 12 months" [20]. While all subjects had knee pain, not all had osteoarthritis. Based on radiograph and magnetic resonance imaging (MRI) cartilage scores, subjects were classified into three subgroups: "no OA" on both MRI and x-ray (both normal) (13\%), "preradiographic OA" on an abnormal MRI (but normal xray) (49\%), and "radiographic OA" on an abnormal x-ray (38\%). Subjects were excluded both at baseline and/or at follow-up if any of the following applied, as described in Cibere et al. [20]: inflammatory arthritis (or fibromyalgia), knee arthroplasty, knee injury or surgery within the past 6 months, knee pain referred from hips or back, or unable to undergo MRI. Of 255 subjects seen at baseline, 122 subjects successfully completed the second followup. Details about reasons for dropout have been described previously in Sayre et al. [21].

\section{Outcomes and predictor variables}

Depression and anxiety were measured via the Hospital Anxiety and Depression Scale (HADS), and the binary outcome variables were based on HADS scales measuring 5+ for depression and 7+ for anxiety [22-24].

Predictor variables related to OA were selected a priori by the study team for clinically relevant items from the literature, or those thought to be clinically relevant, from a much larger set of variables that had been collected on these subjects. We focused on items that are easily accessible to clinical practitioners (such as those measured during a clinical exam, collected via self-reported questionnaire, or scored on a plain radiograph), and/or easily noticeable by (and potentially worrisome to) patients. We identified three major sources of such potential predictors evaluated at baseline.

The first source of potential predictors was derived from a baseline physical examination of the knee. These variables have all previously demonstrated good reliability according to an inter-rater intraclass correlation coefficient (ICC) of at least 0.8 [25]. Data included: alignment by visual inspection (normal/varus/valgus; ICC = 0.94); effusion (present/absent; ICC = 0.97); flexion (degrees; ICC = 0.85); flexion contracture (degrees; ICC = 0.95); crepitus (none/fine/coarse; ICC $=0.96$ ); quadriceps atrophy (none/mild/severe; $\mathrm{ICC}=0.97$ ). Alignment was entered into the models as any malalignment vs. normal alignment. Flexion was dichotomized as $>=135$ vs. $<135$ degrees in the models for ease of interpretation and application by clinicians, who don't use a goniometer to measure flexion; > = 135 was chosen as the cut point due to its representing "normal" flexion. Similarly, flexion contracture was dichotomized as $>=1$ vs. $<1$ degree in the models for ease of interpretation and application by clinicians; > = 1 was chosen as the cut point due 
to its representing the presence of a flexion contracture. Quadriceps atrophy was entered into the models as any atrophy vs. none (i.e., normal).

The second source was derived from a self-reported questionnaire at baseline. Data included: knee swelling in the past 12 months (yes/no); painful joint count using a homunculus; and a previous physician's diagnosis of study knee OA (no/probable/definite). For knee-related questions, information on the study knee was used in the analysis. In subjects with bilateral pain, the worse (more painful) knee was used as the study knee. Subjects also completed the Western Ontario and McMaster Universities (WOMAC) Osteoarthritis Index VA3.1 [26]. WOMAC scales for pain and stiffness were normalized to a 0-100 range (higher worse), and dichotomized for ease of interpretation and application by clinicians as $25+$ vs. $<25$ in the analysis; 25 was chosen as the cutpoint for pain based on the univariate distribution (75th percentile), and was also used for stiffness for consistency as it was numerically close to that 75th percentile.

The third source was derived from an x-ray at baseline, obtained using a weight-bearing fixed-flexion posteroanterior view with the SynaFlexer (BioClinica Inc., Newark, CA) positioning frame, and a skyline view in the supine position [27]. Radiographs were read blinded to clinical information, and read and scored by two independent readers for Kellgren-Lawrence (KL) 0-4 grading [28]. Previous studies using these data have demonstrated good interrater reliability $(\mathrm{ICC}=0.79)$ [29]. Differences in readings were adjudicated by consensus readings with both readers. Baseline KL grade was collapsed into $0,1,2$ or $3+$ in the analysis. KL grades 3 and 4 were collapsed due to distribution-only $6 \%$ had KL grade 4 at baseline.

Finally, age decade, sex and body mass index (BMI) $\geq 25$ (representing overweight) were included as potential predictors.

\section{Statistical analysis}

Baseline data were summarized using frequencies or means (+ standard deviation), stratified separately by baseline depression and anxiety. Logistic regression was used to model binary depression and anxiety at baseline, as well as at first and second follow-up. In the follow-up models for depression, those with depression at baseline were excluded. Similarly, in the follow-up models for anxiety, those with anxiety at baseline were excluded. Multivariable models were selected via lowest Akaike's information criterion (AIC), with the additional restriction of $p$-values $<$ alpha $=0.15$. The $p$-value $<0.15$ restriction was not a pre-screening, but rather imposed during selection, and was meant to prevent possible instability in the model if variables less significant than that were included. Odds ratios (ORs) along with 95\% confidence intervals (CIs) were computed from each selected model. Model fit was assessed via the Hosmer and Lemeshow goodness of fit test, which is based on the agreement between observed and predicted probabilities [30]. In addition to selecting models on the basis of predictive utility via lowest AIC, the predictive utility of each selected multivariable model was also assessed via area under the receiver operating characteristic (ROC) curve (AUC), which were reported along with their 95\% confidence intervals.

For consistency, the primary analysis utilized the common sample that was successfully followed to 7.5 years in all three analyses (baseline, 3-year and 7.5-year models). However, this could raise the question about a possible survival bias. To assess whether this may have played a role in any observed associations, we performed additional sensitivity analyses in which the selected multivariable models at first follow-up and baseline were refit using all available data for their respective time points, rather than only the smaller sample followed to 7.5 years. In addition to this, we compared baseline covariates as well as baseline and 3-year follow-up depression and anxiety in the portion of the baseline sample that was followed up to 7.5 years vs. the portion that was not, via chi-square tests for categorical variables, or ttests for continuous variables.

To obtain population-based estimates, all analyses were performed using age decade-gender stratum sampling weights [20]. This was required as the original sample was collected in a manner to ensure adequate sample sizes across all in-scope age decade-gender groups (namely 40-79 male/female), for example older age decades were over-sampled and younger decades under-sampled. Descriptive statistics are also reported using the sampling weight, for population representativeness and to reflect the data used in the models.

All analyses were performed using SAS v9.4 (SAS Institute, Cary, North Carolina).

\section{Results}

This cohort study included 122 subjects with data at baseline and follow-up. The median follow-up time was 3.2 years at first follow-up (range 2.5 to 5.1), and 7.5 years at second follow-up (range 6.0 to 9.5). Sampleweighted baseline characteristics, stratified separately by baseline depression and anxiety, are shown in Table 1. Non-depressed (weighted $N=97.0$ ), compared to depressed subjects (weighted $N=25.0$ ), differed significantly in proportion female $(61.4 \%$ vs. $33.9 \%)$ and KL grade. Non-depressed subjects had substantially fewer KL grade 1 knees (14.4\% vs. $40.2 \%)$, more KL grade 2 $(25.7 \%$ vs. $10.0 \%)$, and similar proportions with KL grades $0(42.0 \%$ vs. $35.7 \%)$ and $3+(17.9 \%$ v. $14.1 \%)$. The 
Table 1 Sample-weighted baseline characteristics

\begin{tabular}{|c|c|c|c|c|}
\hline & $\begin{array}{l}\text { No baseline depression } \\
\text { (Weighted } N=97.0 \text { ) }\end{array}$ & $\begin{array}{l}\text { Baseline depression } \\
\text { (Weighted } N=25.0 \text { ) }\end{array}$ & $\begin{array}{l}\text { No baseline anxiety } \\
\text { (Weighted } N=90.0 \text { ) }\end{array}$ & $\begin{array}{l}\text { Baseline anxiety } \\
\text { (Weighted } N=32.0 \text { ) }\end{array}$ \\
\hline Age, mean (SD) & $55.5(9.0)$ & $55.8(9.9)$ & $56.5(8.8)$ & $52.9(9.0)$ \\
\hline \multicolumn{5}{|l|}{ Age decade, n (\%) } \\
\hline $40-49$ & $21.6(22.3)$ & $9.0(36.1)$ & $16.4(18.2)$ & $14.2(44.5)$ \\
\hline $50-59$ & $47.8(49.3)$ & $6.7(26.7)$ & $41.7(46.3)$ & $12.8(39.9)$ \\
\hline $60-69$ & $17.8(18.4)$ & $5.1(20.2)$ & $21.4(23.7)$ & $1.5(4.8)$ \\
\hline $70-79$ & $9.8(10.1)$ & $4.2(17.0)$ & $10.6(11.8)$ & $3.5(10.8)$ \\
\hline Female, n (\%) & $59.5(61.4)$ & $8.5(33.9)$ & $48.8(53.8)$ & $19.5(61.1)$ \\
\hline Body mass index, mean (SD) & $25.9(4.2)$ & $26.5(3.3)$ & $26.2(4.0)$ & $25.7(4.1)$ \\
\hline $\mathrm{BMI} \geq 25, \mathrm{n}(\%)$ & $49.9(51.4)$ & $17.4(69.6)$ & $51.5(57.2)$ & $15.8(49.4)$ \\
\hline Effusion, n (\%) & $17.9(18.5)$ & $6.0(24.0)$ & $16.1(17.9)$ & $7.8(24.6)$ \\
\hline \multicolumn{5}{|l|}{ Crepitus, n (\%) } \\
\hline None & $29.2(30.2)$ & $8.5(34.0)$ & $27.0(29.9)$ & $10.8(33.8)$ \\
\hline Fine & $49.6(51.1)$ & $11.9(47.4)$ & $45.2(50.2)$ & $16.3(50.9)$ \\
\hline Coarse & $18.2(18.7)$ & $4.6(18.5)$ & $17.9(19.9)$ & $4.9(15.3)$ \\
\hline Malalignment, n (\%) & $11.5(11.9)$ & $4.6(18.3)$ & $10.7(11.9)$ & $5.4(16.9)$ \\
\hline Quadriceps atrophy, n (\%) & $30.5(31.4)$ & $7.5(30.0)$ & $25.2(27.9)$ & $12.8(40.1)$ \\
\hline Flexion (degrees), mean (SD) & $134.3(8.6)$ & $133.2(6.9)$ & $134.4(8.0)$ & $133.2(8.8)$ \\
\hline $\begin{array}{l}\text { Flexion contracture (deg.), mean } \\
\text { (SD) }\end{array}$ & $1.5(3.9)$ & $1.7(2.8)$ & $1.8(3.9)$ & $0.6(2.7)$ \\
\hline \multicolumn{5}{|l|}{ Kellgren-Lawrence grade, n (\%) } \\
\hline 0 & $40.8(42.0)$ & $8.9(35.7)$ & $36.1(40.1)$ & $13.6(42.6)$ \\
\hline 1 & $14.0(14.4)$ & $10.0(40.2)$ & $17.1(19.0)$ & $6.9(21.6)$ \\
\hline 2 & $24.9(25.7)$ & $2.5(10.0)$ & $19.9(22.1)$ & $7.5(23.5)$ \\
\hline $3+$ & $17.3(17.9)$ & $3.5(14.1)$ & $16.9(18.8)$ & $3.9(12.3)$ \\
\hline WOMAC pain, mean (SD) & $18.0(16.4)$ & $23.4(19.9)$ & $18.1(16.5)$ & $21.9(19.5)$ \\
\hline WOMAC pain $(25+)$ & $23.8(24.6)$ & $8.4(33.7)$ & $22.6(25.1)$ & $9.7(30.4)$ \\
\hline WOMAC stiffness, mean (SD) & $2.4(2.4)$ & $2.1(1.9)$ & $2.3(2.4)$ & $2.3(2.0)$ \\
\hline WOMAC stiffness (25+) & $38.1(39.3)$ & $11.1(44.5)$ & $35.7(39.6)$ & $13.6(42.4)$ \\
\hline $\begin{array}{l}\text { Self-reported knee swelling in last } \\
12 \text { months, } \mathrm{n}(\%)\end{array}$ & $54.8(56.5)$ & $16.5(66.0)$ & $46.3(51.4)$ & $25.1(48.5)$ \\
\hline Painful joint count, mean (SD) & $7.8(6.8)$ & $9.4(12.3)$ & $7.5(7.0)$ & $9.8(11.4)$ \\
\hline \multicolumn{5}{|l|}{ Previous physician diagnosis knee OA } \\
\hline No & $57.1(58.9)$ & $16.3(65.4)$ & $56.6(62.9)$ & $16.8(52.7)$ \\
\hline Probable & $30.4(31.3)$ & $6.1(24.4)$ & $24.9(27.7)$ & $11.6(36.2)$ \\
\hline Definite & $9.5(9.8)$ & $2.6(10.3)$ & $8.5(9.5)$ & $3.6(11.2)$ \\
\hline
\end{tabular}

WOMAC = Western Ontario and McMaster Universities (WOMAC) Osteoarthritis Index VA3.1

non-depressed vs. depressed cohorts were similar on mean age ( 55.5 years vs. 55.8 years) and age decade, and all other assessed variables (Table 1). Non-anxious (weighted $N=90.0$ ), compared to anxious (weighted $N=$ 32.0), differed significantly on flexion contracture (mean 1.8 degrees vs. 0.6 degrees), self-reported knee swelling $(51.4 \%$ vs. $48.5 \%)$, and age decade (the anxious cohort tended to be younger). However, the non-anxious vs. anxious cohorts did not differ significantly on mean age
( 56.5 years vs. 52.9 years) and all other assessed variables (Table 1).

Table 2 lists the adjusted odds ratios from the selected prediction models for depression. The selected model for baseline depression (AUC 0.722; 95\% CI $=0.624$, 0.819 ) included sex (female $\mathrm{OR}=0.27 ; 0.10,0.76$ ) and $\mathrm{KL}$ grade (KL 1 [pre-radiographic $\mathrm{OA}$ ] $\mathrm{OR}=4.21 ; 1.31$, 13.48). The 3.2-year depression model (AUC 0.742; 95\% $\mathrm{CI}=0.622,0.862)$ included $\mathrm{KL}$ grade $(\mathrm{KL} 1 \mathrm{OR}=18.92$; 
Table 2 Odds ratios in selected multivariable models predicting depression

\begin{tabular}{llll}
\hline Parameter & $\begin{array}{l}\text { Baseline } \\
\text { OR }(95 \% \mathrm{Cl})\end{array}$ & $\begin{array}{l}\text { First follow-up } \\
\text { OR }(95 \% \mathrm{Cl})\end{array}$ & $\begin{array}{l}\text { Second follow-up } \\
\text { OR }(95 \% \mathrm{Cl})\end{array}$ \\
\hline Female & $0.27(0.10,0.76)$ & - & - \\
Kellgren-Lawrence grade & & & - \\
$\quad 1$ vs. 0 & $4.21(1.31,13.48)$ & $18.92(1.73,206.25)$ & - \\
2 vs. 0 & $0.45(0.09,2.19)$ & $1.49(0.07,33.60)$ & - \\
$\quad 3+$ vs. 0 & $0.64(0.15,2.72)$ & $2.50(0.11,54.96)$ & - \\
Malalignment & $4.38(1.08,17.77)$ & - & - \\
WOMAC stiffness (25+) & - & - & $3.49(1.02,11.94)$ \\
Flexion contracture (degrees) $\geq 1$ & - & - & $0.23(0.07,0.81)$ \\
\hline
\end{tabular}

Western Ontario and McMaster Universities (WOMAC) Osteoarthritis Index pain 0-100 scale

- = Not in selected model

1.73, 206.25). The 7.5-year depression model (AUC 0.606; $95 \% \mathrm{CI}=0.487,0.725)$ included WOMAC stiffness $\geq 25(\mathrm{OR}=3.49 ; 1.02,11.94)$ and flexion contracture $\geq 1$ degree $(\mathrm{OR}=0.23 ; 0.07,0.81$ ).

Table 3 lists the adjusted odds ratios from the selected prediction models for anxiety. The selected model for baseline anxiety (AUC 0.749; 95\% CI $=0.653,0.846$ ) included age decade and knee swelling $(\mathrm{OR}=4.11 ; 1.51$, 11.13). 50-59 and 60-69 age groups were protective vs. 40-49: 50-59 OR $=0.31(0.11,0.85) ; 60-69$ OR $=0.07$ $(0.01,0.42)$. The 3.2 -year anxiety model (AUC 0.739; $95 \% \mathrm{CI}=0.622,0.856)$ included WOMAC stiffness $\geq 25$ $(\mathrm{OR}=5.80 ; 1.23,27.29)$ and $\mathrm{KL}$ grade $(\mathrm{KL} 1 \mathrm{OR}=6.25$; $1.04,37.65$ ). The 7.5-year anxiety model (AUC 0.587; $95 \% \mathrm{CI}=0.490,0.685)$ included sex (female $\mathrm{OR}=2.71$; $0.87,8.46)$.

In sensitivity analyses in which the selected multivariable models at baseline were re-fit using all available data for that time point $(N=255)$, the directions of the significant associations in the baseline and first followup models remained consistent across the depression and anxiety models. Finally, in the comparison of baseline covariates as well as baseline and 3-year follow-up depression and anxiety in the portion of the baseline sample that was successfully followed up to 7.5 years vs. the portion that was not, those who were followed had significantly more self-reported swelling $(58.5 \%$ vs. $43.8 \%, p=0.019)$. There were no other significant differences.

All selected multivariable models passed the Hosmer and Lemeshow goodness of fit test.

\section{Discussion}

We developed prediction models for depression and anxiety (current, 3-year and 7.5 years out) from a variety of easily accessible potential predictors including those sourced from physical examination, self-reported questionnaire, and radiographic evaluation, in a longitudinal population-based cohort with knee pain.

Cross-sectionally, male sex and malalignment were predictive of depression, as was KL grade 1 when compared to grade 0 . Grades 2 and $3+$ were not significant.

Table 3 Odds ratios in selected multivariable models predicting anxiety

\begin{tabular}{|c|c|c|c|}
\hline Parameter & $\begin{array}{l}\text { Baseline } \\
\text { OR ( } 95 \% \mathrm{Cl})\end{array}$ & $\begin{array}{l}\text { First follow-up } \\
\text { OR }(95 \% \mathrm{Cl})\end{array}$ & $\begin{array}{l}\text { Second follow-up } \\
\text { OR }(95 \% \mathrm{Cl})\end{array}$ \\
\hline \multicolumn{4}{|l|}{ Age decade } \\
\hline $50-59$ vs. $40-49$ & $0.31(0.11,0.85)$ & - & - \\
\hline $60-69$ vs. $40-49$ & $0.07(0.01,0.42)$ & - & - \\
\hline $70-79$ vs. $40-49$ & $0.32(0.07,1.41)$ & - & - \\
\hline Self-reported knee swelling last 12 months & $4.11(1.51,11.13)$ & - & - \\
\hline WOMAC stiffness (25+) & - & $5.80(1.23,27.29)$ & - \\
\hline \multicolumn{4}{|l|}{ Kellgren-Lawrence grade } \\
\hline 1 vs. 0 & - & $6.25(1.04,37.65)$ & - \\
\hline 2 vs. 0 & - & $0.70(0.08,6.16)$ & - \\
\hline $3+$ vs. 0 & - & $1.95(0.29,13.18)$ & - \\
\hline Female & - & - & $2.71(0.87,8.46)$ \\
\hline
\end{tabular}

Western Ontario and McMaster Universities (WOMAC) Osteoarthritis Index pain 0-100 scale - = Not in selected model 
One seemingly plausible explanation for this unusual pattern is adaptation to the diagnosis by the time advanced disease sets in. At first follow-up, the same pattern of association is seen vs. KL grade, with no other predictors in the model. At second follow-up, WOMAC stiffness $\geq 25$ was predictive of depression, while presence of a flexion contracture was protective. Crosssectionally, predictors of anxiety included age decade (50-59 and 60-69 age decades were protective compared to 40-49), and self-reported knee swelling (harmful). That self-reported knee swelling would induce anxiety is not surprising. At first follow-up, baseline predictors of anxiety included WOMAC stiffness (positive association), and $\mathrm{KL} x$-ray grade, with essentially the same pattern as that observed in the depression models. At second follow-up, only female sex was predictive of anxiety, though it was not significant.

The previous literature on this topic is somewhat scant. Of the studies we identified that investigated OArelated predictors of depression or anxiety [6-19], the majority were cross-sectional, and/or explored only the gross association between OA disease as a whole and depression or anxiety. Four studies investigated possible OA-related predictors of future depression or anxiety. Peruccio et al. [12] reported significant positive associations between the number of painful joints preoperatively, and HADS depression and anxiety scales 1 year post-operatively, in a population undergoing knee replacement surgery for OA. Gandhi et al. [13] also reported a positive association between painful joint count and (present) depression and anxiety in a cohort about to undergo knee or hip replacement for OA. In our study, painful joint count was not predictive. It is possible this is due to the cohort entry criteria, which included "pain, aching, or discomfort in or around the knee on most days of the month at any time in the past" (i.e., all subjects had some history of persistent knee pain). In another cohort of preoperative knee and hip osteoarthritis, Wood et al. [11] modelled (present) depression and anxiety versus pain severity, Oxford Score, and $\mathrm{KL}$ grade, adjusting for other covariates. The only significant predictor of anxiety they identified was Oxford Score, while for depression both pain and Oxford were predictive. Partially in line with this, we identified WOMAC stiffness as a significant predictor of (future) anxiety and depression.

On the other hand, in a non-preoperative study, Hawker et al. [19] found that disability and fatigue predicted future depression in OA, while pain was not predictive. Similarly, White et al. [16] reported slow gait speed as predictive of worsening depressive symptoms in knee OA. Pain was also not predictive in our multivariable models. Touching on another of our findings, Brandt et al. [17] found a significant relationship between knee pain without OA diagnosis and depression, yet they did not observe this within OA diagnosed subjects. This is in line with our findings with KL grade 1 being predictive, while grades 2 and $3+$ are not (again, possibly due to adaptation). Finally, Shimura et al. [18] reported an association between serum interleukin 6 (an inflammatory cytokine) and depressive state, which may be analogous to our finding that self-reported knee swelling cross-sectionally predicts anxiety.

The strengths and limitations of our study deserve comment. While population-based is a strength, it should also be noted that the target population is not the overall population, but those with baseline knee pain, aged 40-79 at baseline, who were successfully followed up over an average of 7.5 years. As such, we cannot be sure that the results of this study are applicable to a more general population. However, considering our objective was to develop prediction models for anxiety and depression from manifestations of OA (an inherently painful disease), this restriction should not be too impactful, and further, our inclusion of mild but persistent knee pain without diagnosed OA actually presents an $e x$ panded target population compared to some of the comparable literature discussed above. Another strength of this study is a priori selected potential predictors based on literature as well as subject matter expertise. Another limitation of this study is loss to follow-up: only 122 of the original 255 baseline subjects were successfully followed through to the third cycle. To explore the effect this might have had, we analyzed potential differences between those followed to 7.5 years vs. not followed to 7.5 years on all the covariates included in this analysis as well as baseline and 3-year follow-up depression and anxiety, and found no significant differences amongst depression and anxiety or those variables included in the final selected models, except self-reported swelling. Furthermore, in sensitivity analyses, models fit on the larger samples available at each time point were generally consistent with the primary results. It should be acknowledged that data not missing at random (and the bias that could result) may have impacted the models. For example, if subjects with severe OA (advanced KL grade) who were depressed at follow-up were less likely to provide follow-up data than those who were not depressed, then this could produce a conservative bias towards the null. It is also conceivable that other biases could be liberal in direction, for example, if subjects with severe OA who were depressed at follow-up were more likely to provide follow-up data than their non-depressed counterparts (less plausible). Finally, the point estimates reported in this study should be interpreted with some caution, considering the width of many of the confidence intervals. Wide confidence intervals may have resulted from small cell sizes, for example, KL grade $3+$ 
with depression at first follow-up contained only three subjects, producing a particularly wide confidence interval.

\section{Conclusions}

We have developed cross-sectional and longitudinal (at 3 and 7 years) prediction models for depression and anxiety from specific manifestations of OA, drawing from a broad array of potential predictors from a variety of sources (i.e., physical exam, self-reported questionnaire, and radiographic evaluation), in a population with knee pain with or without an OA diagnosis. These models may prove useful to clinicians in helping to identify patients most at risk of either present or future depression and anxiety, thus facilitating preemptive discussions that may help counter that risk.

\section{Abbreviations}

OA: Osteoarthritis; MRI: Magnetic resonance imaging; HADS: Hospital Anxiety and Depression Scale; ICC: Intraclass correlation coefficient; WOMAC: Western Ontario and McMaster Universities; KL: Kellgren-Lawrence; BMI: Body mass index; ROC: Receiver operating characteristic; AUC: Area under the ROC curve; AIC: Akaike's information criterion

\section{Acknowledgements}

We wish to thank the participants in this study as well as the research staff.

\section{Authors' contributions}

All authors on this manuscript made significant contributions to the study design. JC, AG, JME and SN were responsible for data acquisition. All authors were involved in the analysis and interpretation of data. ECS and JC drafted the manuscript. All authors were involved in revising the manuscript, and gave final approval of the version to be published. All authors agree both to be personally accountable for the author's own contributions and to ensure that questions related to the accuracy or integrity of any part of the work, even ones in which the author was not personally involved, are appropriately investigated, resolved, and the resolution documented in the literature.

\section{Funding}

This cohort study was funded by grants from the Canadian Institutes of Health Research (\#89890, Cibere; \#89997, Cibere), the Canadian Arthritis Network (01-MNO-09 N, Cibere) and The Arthritis Society (TAS04/0063, (ibere). Dr. Cibere was supported by an Investigator Award from The Arthritis Society (INS-12-027). The funders had no role in study design, data collection and analysis, decision to publish, or preparation of the manuscript.

\section{Availability of data and materials}

The datasets used and analyzed during the current study are available from the corresponding author on reasonable request.

\section{Ethics approval and consent to participate}

All subjects provided written informed consent. The study was conducted in accordance with the Declaration of Helsinki and was approved by the Clinical Research Ethics Board, University of British Columbia with approval number \#H09-02046.

\section{Consent for publication}

Not applicable.

\section{Competing interests}

Ali Guermazi is President of Boston Imaging Core Lab, LLC, and consultant to AstraZeneca, TissueGene, Roche, Galapagos, Merck Serono and Pfizer. No other authors have competing interests to declare.

\section{Author details}

'Arthritis Research Canada, 5591 No. 3 Road, Richmond, BC V6X 2C7, Canada. ${ }^{2}$ Medicine, University of British Columbia, Vancouver, BC, Canada. ${ }^{3}$ Medicine, University of Calgary, Calgary, AB, Canada. ${ }^{4}$ School of Population \& Public Health, University of British Columbia, Vancouver, BC, Canada. ${ }^{5}$ Radiology, Boston University School of Medicine, Boston, MA, USA. ${ }^{6}$ Radiology, University of British Columbia, Vancouver, BC, Canada.

Received: 16 October 2019 Accepted: 9 July 2020

Published online: 16 July 2020

\section{References}

1. Kopec JA, Rahman MM, Berthelot JM, Le Petit C, Aghajanian J, Sayre EC, et al. Descriptive epidemiology of osteoarthritis in British Columbia, Canada. J Rheumatol. 2007;34:386-93.

2. Lawrence RC, Felson DT, Helmick CG, Arnold LM, Choi H, Deyo RA, et al. Estimates of the prevalence of arthritis and other rheumatic conditions in the United States. Arthritis Rheum. 2008;58:26-35.

3. Felson DT, Naimark A, Anderson J, Kazis L, Castelli W, Meenan RF. The prevalence of knee osteoarthritis in the elderly - the Framingham osteoarthritis study. Arthritis Rheum. 1987;30:914-8.

4. Bombardier C HG, Mosher D, Arthritis Alliance of Canada. The impact of arthritis in canada : Today and over the next 30 years. 2016. Available from: http://www.arthritisalliance.ca/images/PDF/eng/Initiatives/20111022_2200_ impact_of_arthritis.pdf.

5. Axford J, Butt A, Heron C, Hammond J, Morgan J, Alavi A, et al. Prevalence of anxiety and depression in osteoarthritis: use of the hospital anxiety and depression scale as a screening tool. Clin Rheumatol. 2010;29:1277-83.

6. Rana AQ, Qureshi AR, Akhter S, Ingar Y, Ayub A, Abdullah I, et al. Osteoarthritis increases paresthestic and akathisic pain, anxiety case-ness, and depression severity in patients with parkinson's disease. Front Neurol. 2018;9:409. https://doi.org/10.3389/fneur.2018.00409.

7. Liao X, Mao CP, Wang Y, Zhang QF, Cao DY, Seminowicz DA, et al. Brain gray matter alterations in chinese patients with chronic knee osteoarthritis pain based on voxel-based morphometry. Medicine. 2018;97(12):e0145. https://doi.org/10.1097/MD.0000000000010145.

8. Jung JH, Seok H, Kim JH, Song GG, Choi SJ. Association between osteoarthritis and mental health in a korean population: a nationwide study. Int J Rheum Dis. 2018:21:611-9.

9. Schuring N, Aoki H, Gray J, Kerkhoffs G, Lambert M, Gouttebarge V. Osteoarthritis is associated with symptoms of common mental disorders among former elite athletes. Knee Surg Sports Traumatol Arthrosc. 2017;25: 3179-85.

10. Duarte N, Rodrigues AM, Branco JD, Canhão H, Hughes SL, Paúl C. Health and lifestyles factors associated with osteoarthritis among older adults in Portugal. Front Med. 2017:4:192. https://doi.org/10.3389/fmed.2017.00192.

11. Wood TJ, Thornley P, Petruccelli D, Kabali C, Winemaker M, de Beer J. Preoperative predictors of pain catastrophizing, anxiety, and depression in patients undergoing total joint arthroplasty. J Arthroplast. 2016;31:2750-6.

12. Perruccio AV, Power JD, Evans HMK, Mahomed SR, Gandhi R, Mahomed NN, et al. Multiple joint involvement in total knee replacement for osteoarthritis: effects on patient-reported outcomes. Arthritis Care Res. 2012;64:838-46.

13. Gandhi R, Zywiel MG, Mahomed NN, Perruccio AV. Depression and the overall burden of painful joints: an examination among individuals undergoing hip and knee replacement for osteoarthritis. Arthritis. 2015;2015: 327161. https://doi.org/10.1155/2015/327161.

14. Scopaz KA, Piva SR, Wisniewski S, Fitzgerald GK. Relationships of fear, anxiety, and depression with physical function in patients with knee osteoarthritis. Arch Phys Med Rehabil. 2009;90:1866-73.

15. Veronese N, Stubbs B, Solmi M, Smith TO, Noale M, Cooper C, et al. Association between lower limb osteoarthritis and incidence of depressive symptoms: data from the osteoarthritis initiative. Age Ageing. 2017:46:470-6.

16. White DK, Neogi T, Zhang YQ, Niu JB, Katz PP. Association of slow gait speed with trajectories of worsening depressive symptoms in knee osteoarthritis: an observational study. Arthritis Care Res. 2017;69:209-15.

17. Brandt KD, Heilman DK, Slemenda C, Katz BP, Mazzuca S, Braunstein EM, et al. A comparison of lower extremity muscle strength, obesity, and depression scores in elderly subjects with knee pain with and without radiographic evidence of knee osteoarthritis. J Rheumatol. 2000;27:1937-46. 
18. Shimura Y, Kurosawa H, Tsuchiya M, Sawa M, Kaneko H, Liu LZ, et al. Serum interleukin 6 levels are associated with depressive state of the patients with knee osteoarthritis irrespective of disease severity. Clin Rheumatol. 2017;36: 2781-7.

19. Hawker GA, Gignac MAM, Badley E, Davis AM, French MR, Li Y, et al. A longitudinal study to explain the pain-depression link in older adults with osteoarthritis. Arthritis Care Res. 2011;63:1382-90.

20. Cibere J, Zhang HB, Thorne A, Wong H, Singer J, Kopec JA, et al. Association of clinical findings with pre-radiographic and radiographic knee osteoarthritis in a population-based study. Arthritis Care Res. 2010;62:1691-8.

21. Sayre EC, Guermazi A, Esdaile JM, Kopec JA, Singer J, Thorne A, et al. Associations between mri features versus knee pain severity and progression: data from the Vancouver longitudinal study of early knee osteoarthritis. PLoS One. 2017;12(5)::0176833. https://doi.org/10.1371/ journal.pone.0176833.

22. Zigmond AS, Snaith RP. The hospital anxiety and depression scale. Acta Psychiatr Scand. 1983;67:361-70.

23. Aylard PR, Gooding JH, McKenna PJ, Snaith RP. A validation-study of 3 anxiety and depression self-assessment scales. J Psychosom Res. 1987;31: 261-8.

24. Singer S, Kuhnt S, Gotze H, Hauss J, Hinz A, Liebmann A, et al. Hospital anxiety and depression scale cutoff scores for cancer patients in acute care. Br J Cancer. 2009;100:908-12.

25. Cibere J, Bellamy N, Thorne A, Esdaile JM, McGorm KJ, Chalmers A, et al. Reliability of the knee examination in osteoarthritis - effect of standardization. Arthritis Rheum. 2004;50:458-68.

26. Bellamy N, Buchanan WW, Goldsmith CH, Campbell J, Stitt LW. Validation-study of womac - a health-status instrument for measuring clinically important patient relevant outcomes to antirheumatic drug-therapy in patients with osteo-arthritis of the hip or knee. J Rheumatol. 1988;15:1833-40.

27. Kothari M, Guermazi A, von Ingersleben G, Miaux Y, Sieffert M, Block JE, et al. Fixed-flexion radiography of the knee provides reproducible joint space width measurements in osteoarthritis. Eur Radiol. 2004;14:1568-73.

28. Kellgren JH, Lawrence JS. Radiological assessment of osteo-arthrosis. Ann Rheum Dis. 1957;16:494-502.

29. Cibere J, Zhang HB, Garnero P, Poole AR, Lobanok T, Saxne T, et al. Association of biomarkers with pre-radiographically defined and radiographically defined knee osteoarthritis in a population-based study Arthritis Rheum. 2009:60:1372-80.

30. Canary JD, Blizzard L, Barry RP, Hosmer DW, Quinn SJ. Summary goodnessof-fit statistics for binary generalized linear models with noncanonical link functions. Biom J. 2016;58:674-90.

\section{Publisher's Note}

Springer Nature remains neutral with regard to jurisdictional claims in published maps and institutional affiliations.

Ready to submit your research? Choose BMC and benefit from:

- fast, convenient online submission

- thorough peer review by experienced researchers in your field

- rapid publication on acceptance

- support for research data, including large and complex data types

- gold Open Access which fosters wider collaboration and increased citations

- maximum visibility for your research: over $100 \mathrm{M}$ website views per year

At BMC, research is always in progress.

Learn more biomedcentral.com/submissions 